\title{
Introducing Volume 12 of Immunotherapy
}

\author{
Daniel Barrett*,1 \\ ${ }^{1}$ Commissioning Editor, Immunotherapy, Future Science Group, Unitec House 2 Albert Place, Albert PI, London N3 1QB, UK \\ *Author for correspondence: d.barrett@futuremedicine.com
}

"we welcome any feedback from our readers, whether that be key topics that you feel should be covered or where you see the field going in the future. We welcome unsolicited research, review and opinion article proposals and would be delighted to hear from you if you are interested in submitting to the journal."

First draft submitted: 18 December 2019; Accepted for publication: 18 December 2019; Published online: 9 January 2020

To all our readers, the Future Medicine editorial office would like to wish you a happy new year and welcome you to Volume 12 of Immunotherapy.

In this foreword, I will highlight a select few articles from Immunotherapy in 2019 that represent the progress made in the field. From Research Articles and Reviews to Editorials and Commentaries, a variety of manuscripts will be featured, covering a wide range of research and opinions showcased in Immunotherapy.

\section{Readership demographics}

In 2019, North America came top for readership of Immunotherapy with $40 \%$ of our readers, with Asia (31\%) and Europe (24\%) following closely (see Figure 1). With the importance of the field and number of breakthroughs continuing to rise, we look forward to seeing the global reach of Immunotherapy grow even further in the coming year.

\section{Editor's Picks from 2019}

My first pick is a Research Article from Michael B Atkins et al. entitled, 'Comparative efficacy of combination immunotherapy and targeted therapy in the treatment of BRAF-mutant advanced melanoma: a matching-adjusted indirect comparison' [1]. This is one of the most downloaded and read articles from Immunotherapy in 2019. It reports on a study comparing a combination therapy made up of nivolumab and ipilimumab against a targeted therapy using the BRAF and MEK inhibitors, and their effectiveness in treating BRAF-mutant advanced melanoma.

The second article I wish to highlight, being one of our most read Commentary articles of 2019, is from Renrick et al. and titled, 'Update on the current revolution in cancer immunotherapy' [2]. It describes the growth of the field of immunotherapy in relation to cancer treatments, covering topics such as checkpoint blockade therapy, CAR-T-cell therapy and the potential of combination immunotherapies.

Next is the very well-read Review article by Schurich et al. entitled, 'Metabolic regulation of CAR T cell function by the hypoxic microenvironment in solid tumors' [3]. This insightful Review covers immunometabolism surrounding the different mechanisms associated with hypoxia in tumor microenvironments, which results in metabolic changes within $T$ cells. This leads into the prospect of new therapies related to $T$ cells and understanding of how to inhibit the changes that occur within the tumor microenvironment.

One of our most downloaded Editorials of 2019, written by Trinath and Bayry, is entitled, 'Current trends with $\mathrm{FOXP}^{+}$regulatory $\mathrm{T}$ cell immunotherapy to contest autoimmunity and inflammation' [4]. This piece looks at recent developments with regulatory $\mathrm{T}$ cells and their roles in immunosuppression, inflammatory mediators and macrophages. It concludes with considering the potential for regulatory $\mathrm{T}$ cells in different therapies.

The Case Report by Asai et al. entitled, 'Management of cardiac tamponade during nivolumab of lung cancer with intrapericardial bleomycin: case report' [5] was also highly popular with our readers last year. It details the successful management of cardiac tamponade caused by nivolumab-induced pseudoprogression in a patient diagnosed with advanced lung adenocarcinoma. It is believed to be the first reported case demonstrating the administration of 


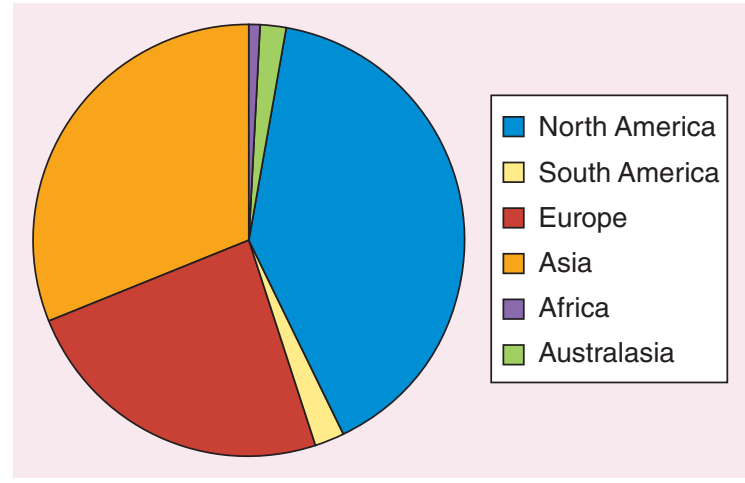

Figure 1. Approximate proportion of readership demographics for Immunotherapy in 2019 by continent.

intrapericardial bleomycin to manage pericardial effusion after immune therapy. The authors conclude that their findings could help with future clinical decisions in the future.

My final pick is a Meta-Analysis by Chen $e$ al. entitled 'The efficacy of PD-1/PD-L1 inhibitors in advanced squamous-cell lung cancer: a meta-analysis of 3112 patients' [6]. Despite having only been published near the end of 2019, this is already a highly read article and we are excited to see this article's reach continue to grow. The meta-analysis included randomized clinical trials comparing the benefits of immunotherapy and chemotherapy for the treatment of advanced squamous non-small-cell lung cancer, and specifically highlights the importance of PD-1/PD-L1 inhibitors, which were shown to significantly improve overall survival and progression-free survival, compared with chemotherapy.

\section{Immunotherapy on Altmetric in 2019}

I would also like to highlight a number of Immunotherapy articles published in 2019 that performed particularly well on Altmetric last year, as we continue our successful partnership with the platform.

First, an Editorial by Shariat et al. entitled 'Six essential conditions for bladder-sparing strategies in bacillus Calmette-Guérin unresponsive bladder cancer' [7] was the most tweeted Immunotherapy article of 2019, with people tweeting about it across the globe.

Another Editorial by Panza et al. entitled 'Are antibodies directed against amyloid- $\beta$ (A $\beta$ ) oligomers the last call for the $A \beta$ hypothesis of Alzheimer's disease?' [8] was not only well tweeted but was also picked up by news outlets and cited in numerous publications.

Finally, a Review by Raman et al. entitled 'Talimogene laherparepvec: review of its mechanism of action and clinical efficacy and safety' [9] was another very popular article in 2019, demonstrated through readership, citation and Altmetric statistics.

\section{Social media}

Immunotherapy encourages our readers to follow us on Twitter (@fsgimt), where we discuss the latest news surrounding immunotherapy, journal highlights and newly published articles. This allows us to engage with our readers along with experts in the field.

\section{Final thoughts}

As always, we welcome any feedback from our readers, whether that be key topics that you feel should be covered or where you see the field going in the future. We welcome unsolicited research, review and opinion article proposals and would be delighted to hear from you if you are interested in submitting to the journal.

I would like to also take this opportunity to thank our readers, esteemed Editorial Board, peer reviewers and contributing authors for their continued support. We very much look forward to working with you all in 2020 and seeing the journal continue to progress.

\section{Financial \& competing interests disclosure}

Daniel Barrett is an employee of Future Medicine Ltd. The author has no other relevant affiliations or financial involvement with any organization or entity with a financial interest in or financial conflict with the subject matter or materials discussed in the manuscript apart from those disclosed.

No writing assistance was utilized in the production of this manuscript. 


\section{References}

1. Atkins MB, Tarhini A, Rael M et al. Comparative efficacy of combination immunotherapy and targeted therapy in the treatment of $B R A F$-mutant advanced melanoma: a matching-adjusted indirect comparison. Immunotherapy 11(7), 617-629 (2019).

2. Renrick AN, Dunbar ZT, Shanker A. Update on the current revolution in cancer immunotherapy. Immunotherapy 11(1), 15-20 (2019).

3. Schurich A, Magalhaes I, Mattsson J. Metabolic regulation of CAR T cell function by the hypoxic microenvironment in solid tumors. Immunotherapy 11(4), 335-345 (2019).

4. Trinath J, Bayry J. Current trends with $\mathrm{FOXP}^{+}$regulatory $\mathrm{T}$ cell immunotherapy to contest autoimmunity and inflammation. Immunotherapy 11(9), 755-758 (2019).

5. Asai M, Kato Y, Kawai S et al. Management of cardiac tamponade during nivolumab of lung cancer with intrapericardial bleomycin: case report. Immunotherapy 11(6), 467-472 (2019).

6. Chen RL, Zhou JX, Cao Y et al. The efficacy of PD-1/PD-L1 inhibitors in advanced squamous-cell lung cancer: a meta-analysis of 3112 patients. Immunotherapy 11(17), 1481-1490 (2019).

7. Shariat SF, Enikeev DV, Mostafaei H. Six essential conditions for bladder-sparing strategies in bacillus Calmette-Guérin unresponsive bladder cancer. Immunotherapy 11(13), 1083-1086 (2019).

8. Panza F, Lozupone M, Dibello V et al. Are antibodies directed against amyloid- $\beta$ (A $\beta$ ) oligomers the last call for the A $\beta$ hypothesis of Alzheimer's disease? Immunotherapy 11(1), 3-6 (2019).

9. Raman SS, Hecht JR, Chan E. Talimogene laherparepvec: review of its mechanism of action and clinical efficacy and safety. Immunotherapy 11(8), 705-723 (2019). 